\title{
DECISIONAL BEHAVIOURS IN NATIONAL SECURITY ORGANIZATIONS
}

\author{
Teodora Dobre \\ Doctoral School of Sociology, University of Bucharest/ "Mihai Viteazul" National Intelligence Academy
}

\begin{abstract}
In the professional literature, the decision-making process is often regarded either through the lens of psychology (debating the factors of influence within the decisional unit) or is placed in a deterministic context (approaching issues such as efficiency in assigning probabilities).

Although decision theory is extensively covered as a stand-alone theory in economy, statistics and psychology, sociology tackles the issue only in relation with other theories such as social exchange, social dilemmas etc. For a sociological understanding of how decisional processes are conducted within a given organization, one must take into account the constraints to which the organization is subject to and the degrees of freedom they allow. Using interdisciplinary desktop research as main method, the present paper aims to inventorize the systemic and sub-systemic constraints that define the national security organizations and identify the key features that can describe, explain or predict decisional behaviours in matters of national security.
\end{abstract}

Keywords: constraints; decision-making process; degrees of freedom; security organizations; systemic approach. 